\title{
THE VALVE OF THE INFERIOR VENA CAVA
}

\author{
BY \\ JOHN B. HICKIE \\ From the Cardiac Department, St. Thomas's Hospital \\ Received August 25, 1955
}

The surgical repair of atrial septal defects (Bailey et al., 1953; Gross et al., 1953; Bjork et al., 1954) has led to a greater awareness of the anatomy of the right atrium. In two cases of this condition we have seen an important variant involving the valve of the inferior vena cava. This structure was described by Bartolomeno Eustachius (1563), but its identity was denied by Bauhin (1605) and not mentioned by Harvey (1628). Winslow (1717) produced the first accurate description of the valve and suggested its fotal function.

Normal Anatomy (Fig. 1). The superior and inferior venæ cavæ open into the sinus venarum which is the smooth medial and posterior wall of the atrium limited on the right side by a vertical muscular ridge, the crista terminalis. All the atrium except this area is ridged with musculi pectinati. The area between the caval orifices is convex towards the atrial cavity, the height of the convexity forming a rounded ridge, the intervenous tubercle of Lower. The oval superior caval orifice is bounded anteriorly by the crista terminalis, medially by the septum and the posterior and lateral margins are continued into the wall of the atrium, the posterior in the region of the tubercle of Lower. The orifice of the inferior cava is also oval, the posterior wall being formed by the septum while it is flanked anteriorly and partly covered by the Eustachian valve or valve of the inferior vena cava (Fig. 1). This structure (Quain, 1929) is a musculomembranous semilunar fold extending posteriorly from the limbus fossa ovalis, anterior to the inferior caval orifice where it disappears. Its free border is usually membranous, concave, and directed upwards and forwards. Its adherent border is a transverse muscular ridge continuous with the anterior margin of the caval orifice. One of its surfaces is turned laterally towards the atrium and the other medially toward the vessel. It is variable in size with an average length of its free edge $3.4 \mathrm{~cm}$. and average width $0.35 \mathrm{~cm}$. (Yater, 1929) the latter seldom exceeding $1 \mathrm{~cm}$. (Drury, 1949). It may be a simple fold or fenestrated or may consist of a network of threads or may be absent.

Anomalies consist of variations in size, extent, muscularity, and Chiari's network (Chiari, 1897), a network of fine fibres from the Eustachian or Thebesian valves to the upper portion of the crista terminalis, interatrial wall, or tricuspid valve; occasionally these may resemble chordæ tendineæ (Pan, 1936). These anomalies are most common in patients with atrial septal defects (Yater, 1929). In front of the anterior end of the Eustachian valve can be seen the circular opening of the coronary sinus which is flanked laterally by the Thebesian valve. This is variable in size, semilunar, often perforated, and usually attached to the lateral edge of the Eustachian valve.

Embryology. The right atrium of the adult heart is developed from the sinus venosus, the primitive atrium, and the right half of the atrial canal (Fig. 2). The sinus venosus opens into the right side of the primitive atrium through a vertically placed opening in the dorsal wall of that chamber, the opening being flanked by the right and left venous valves (Fig. 3). These fuse with one another above the opening in a ridge, the septum spurium. They fuse below and are continued towards the atrial canal. The orifice of the transverse part of the sinus venosus becomes drawn into the posterior wall of the right atrium, and the left valve and septum spurium fuse with the septum secundum (Arey, 1954; Quain, 1929). Bands of muscle form between the openings of the coronary sinus and inferior and superior cavæ so that the original sinus opening and right sinus valve are divided into three parts (Fig. 4): (1) the superior caval opening 


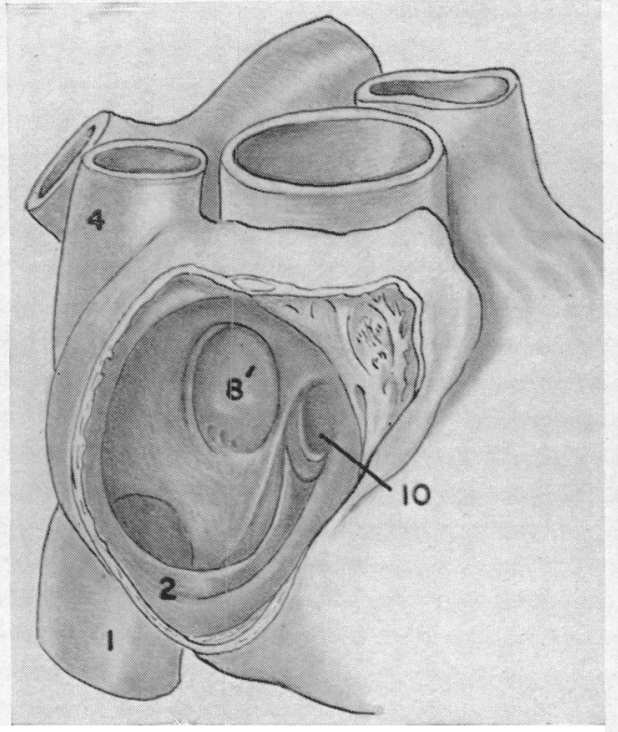

Fig. 1.-Normal anatomy of right atrium.

(1) Inf. vena cava. (2) Eustachian valve.

(4) Sup. vena cava. $\left(8^{\prime}\right)$ Fossa ovalis.

(10) Coronary sinus.

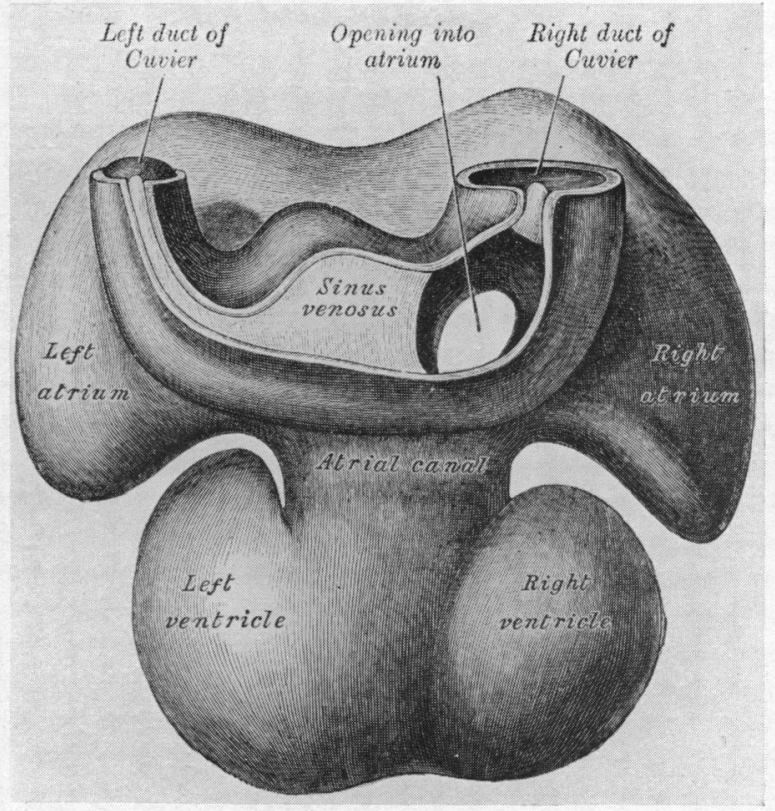

FIG. 2.-The heart of a six-weeks-old embryo, dorsal aspect. (From the model by His-Gray's Anatomy, 30th ed., p. 147.)

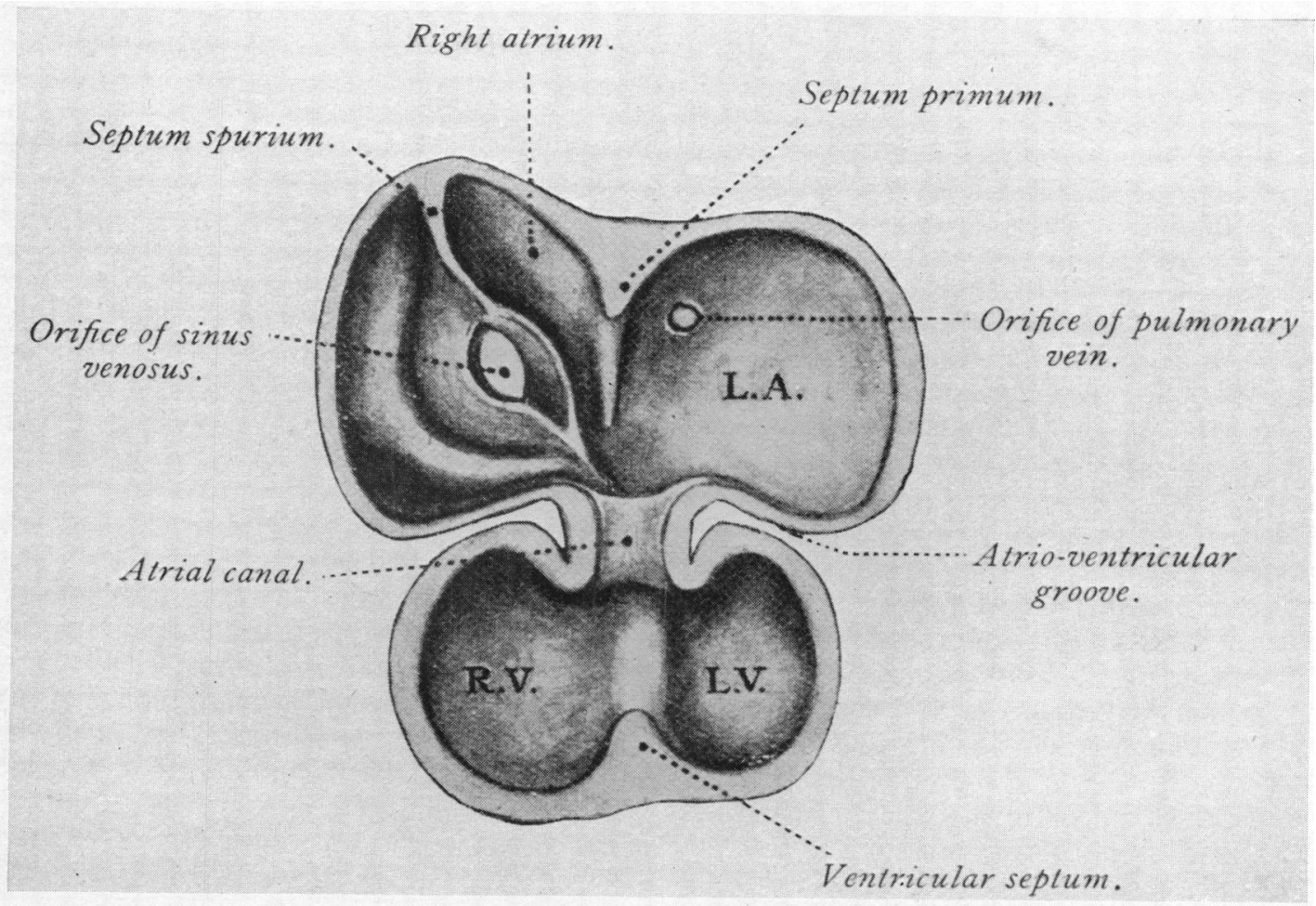

FIG. 3.-The dorsal half of the heart of a human embryo, viewed from the front. (After the model by HisY Quain's Anatomy, 1929, Vol. VI, Part 3, p. 118.) 
ridged above and laterally by the remains of the upper part of the right sinus valve-the crista terminalis; (2) the inferior caval opening bounded in front by the middle half of the right sinus valve-the Eustachian valve; and (3) the coronary sinus bounded on the right by the anterior end of the right sinus valve-the Thebesian valve (Keith, 1904).

The right horn and associated area of the transverse part of the sinus venosus is gradually absorbed into the right atrium and forms the smooth-walled sinus venarum. The primitive atrium forms the auricular appendage and the area of the atrium provided with musculi-pectinati. The right half of the atrial canal forms the smooth area above the atrio-ventricular orifice.

In the fotal heart the free concave cranial border of the Eustachian valve is directed upwards and medially and it directs the blood stream from the inferior vena cava towards the open foramen ovale (Sabatier, 1774 ; Barclay et al., 1944).

\section{CASE REPORTS}

Case 1. A man, aged 47 years. Heart disease had been diagnosed at the age of 4 years. He gave a five-year history of progressive dyspnœa and giddiness on exertion, recurrent chest infections, left præcordial pain, with paroxysmal nocturnal dyspnœa in the last three months.

On examination there was dyspnœa at rest, central cyanosis, and raised jugular venous pressure. There was præcordial prominence with a palpable impulse over the right ventricle and pulmonary artery. Mitral systolic and mid-diastolic murmurs were present and at the pulmonary area a loud systolic click, an accentuated single second sound, and an early diastolic murmur. Scattered râles and rhonchi were heard over both sides of the chest. In the electrocardiogram there was right ventricular hypertrophy and a P-R interval of $0.24 \mathrm{sec}$. Radioscopy showed large and pulsatile pulmonary arteries, right ventricular enlargement, and a normal left atrium. Cardiac catheterization 
and oximetry demonstrated a shunt from left to right and from right to left in the atrium. A pulmonary artery pressure of $105 / 45$ was recorded and the catheter entered an anomalous pulmonary vein from the right lower lobe.

Operation. The right atrium was large and thin-walled. All the right pulmonary veins opened into the right atrium. An atrioseptopexy (Bailey et al., 1953) was contemplated and three observers felt inside the atrium. The superior vena cava, anomalous pulmonary vein, and coronary sinus openings were identified. An extremely large Eustachian valve was felt but the inferior caval opening could not be located. A regurgitant jet was recognized coming from the tricuspid valve. Two defects were felt distant from the atrial wall but their margins were identified with difficulty because of the Eustachian valve. The surgeon felt at first an inferior rim to the larger defect but subsequently considered this was the crescentic fold of the Eustachian valve. Palpation of the mitral valve was not possible. Various manœuvres were tried but all caused a marked drop in oxygen saturation. Unfortunately the patient died four hours later.

Necropsy. The heart was enlarged with hypertrophy and dilatation of the right ventricle (Fig. 5). A dilated right atrium was divided into two chambers, the sinus venarum and the dilated auricular appendage, by the Eustachian valve. This structure arose on the right wall of the atrium in the

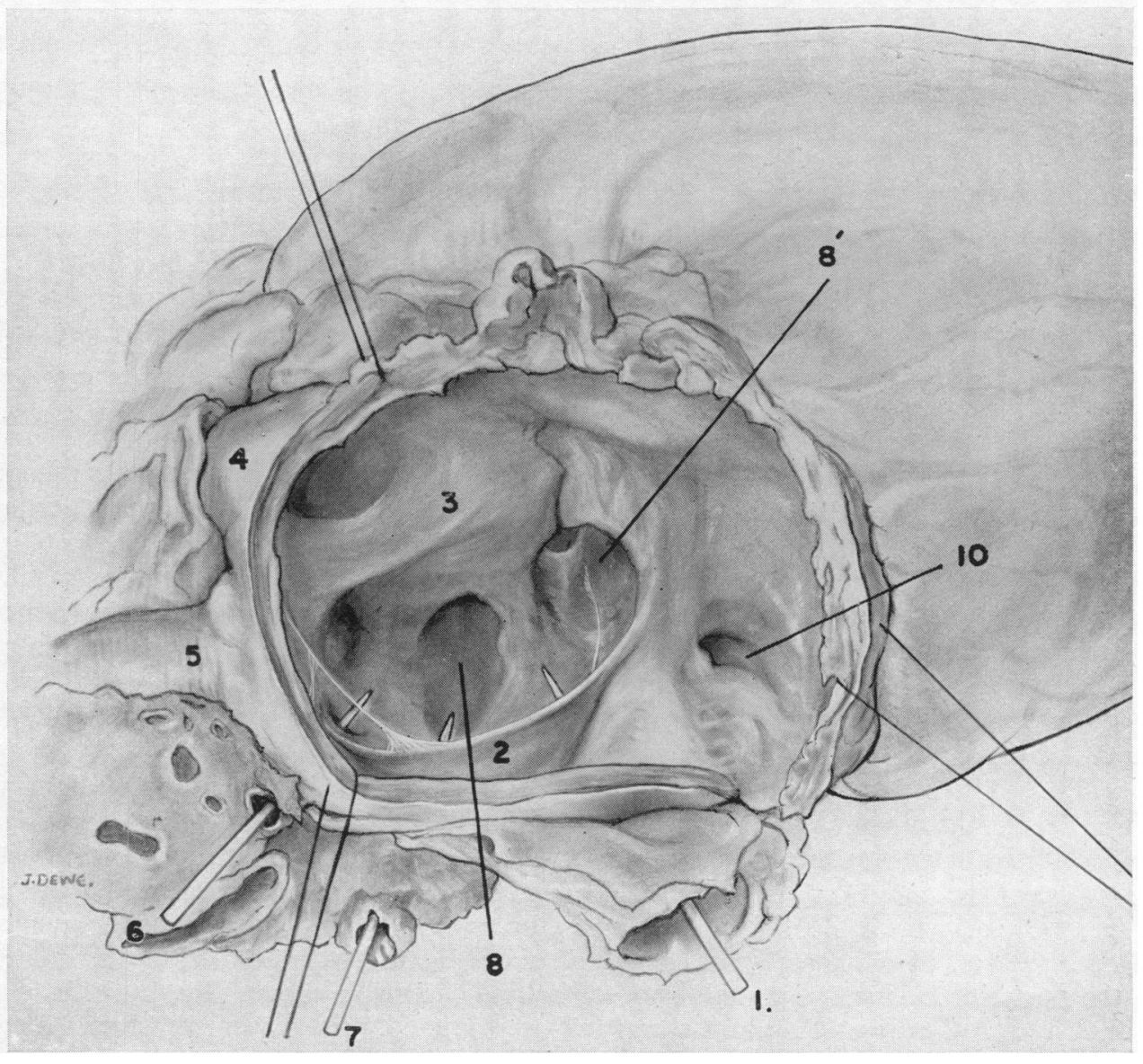

FIG. 5.-Drawing of the right atrium in Case 1. (1) Inferior vena cava. (2) Eustachian valve. (3) Tubercle of Lower. (4) Superior vena cava. (5) Superior pulmonary veins. (6) Middle pulmonary veins. (7) Inf. pulmonary veins. (8) Atrial septal defect. (8') Foramen ovale. (10) Coronary sinus. 
region of the crista terminalis, descended forwards and to the left above the opening of a normal coronary sinus and then proceeded upwards fusing with the anterior limb of the limbus fossa ovalis. It was $6.2 \mathrm{~cm}$. along its free membranous edge, $2.1 \mathrm{~cm}$. wide, and $0.5 \mathrm{~cm}$. thick at its muscular base. The valve was perforated at the musculo-membranous junction and from its right edge arose a network of lace-like fibres which extended to the upper part of the crista terminalis, a Chiari's network (Chiari, 1837). A similar single strand extended from the left posterior aspect of the valve to the fossa ovalis. Above the fossa ovalis was a very prominent intervenous tubercle of Lower which, in combination with the Eustachian valve, produced a ring of tissue that one could readily mistake for a septal defect.

At the right end of the valve was a rounded edge between the inferior caval opening and the right inferior pulmonary vein, and above this the openings of the middle and superior pulmonary veins. On the medial wall of the atrium was the fossa ovalis with a patent foramen ovale. Above this was an atrial septal defect $2.5 \mathrm{~cm}$. in diameter, with a thick rounded antero-inferior rim but no postero-superior margin. The structure of this rim was in contrast with the sharp thin edge of the Eustachian valve. The tricuspid valve was incompetent admitting four fingers but its cusps were normal. The mitral valve admitted only the finger tip, the cusps, especially the antero-medial, being fibrous. The pulmonary artery was large and the remainder of the heart was normal.

Case 2. A man, aged 27 years. Heart disease had been diagnosed at one year. There was a history of seven years of increasing breathlessness, recurrent bronchitis, once with hæmoptysis and left inframammary pain, and giddiness on exertion for seven months.

On examination there was dyspnœa at rest, central cyanosis, præcordial prominence, and a palpable impulse over the right ventricle and pulmonary trunk. There was a pulmonary systolic murmur and a split accentuated second sound. Scattered râles and rhonchi were present over both sides of the chest. In the electrocardiogram there was incomplete right bundle-branch block. Radioscopy showed right ventricular enlargement and large pulsating pulmonary arteries. A cardiac catheter passed through an atrial septal defect and also entered two anomalous right pulmonary veins.

Operation. The right atrium was dilated. Two right superior pulmonary veins entered the lower end of the superior vena cava below the azygos vein. The openings of the middle and inferior pulmonary veins were palpated within the right atrium, the latter vein being closely related to the inferior caval opening. An atrial septal defect with an antero-superior rim was identified. An atrioseptopexy (Bailey et al., 1953) was performed and the oxygen saturation fell to 60 per cent (oximeter). Further manipulations raised it to 85 per cent which was 5 per cent below preoperative level. There appeared to be a free pathway to both cavæ. Postoperatively the patient was dyspnœic and disorientated with an oxygen saturation of 60 per cent. Further cardiotomy was done and nine sutures removed without improvement, but when the tenth and most inferior suture (lying $1.8 \mathrm{~cm}$. anterior to the entry of the inferior cava). was taken away the oxygen saturation rose to 95 per cent. The patient died suddenly two hours later.

Necropsy. The heart was enlarged with hypertrophy and dilatation of the right ventricle (Fig. 6). The right atrium was dilated and the Eustachian valve commenced on its right wall, descended forwards and to the left above the coronary sinus, and continued on to the medial wall in the region of the anterior edge of the septal defect. The valve was muscular, $4.7 \mathrm{~cm}$. along its free edge, $1.5 \mathrm{~cm}$. wide, and $0.7 \mathrm{~cm}$. thick at its base. On the medial wall of the atrium was a septal defect $3 \mathrm{~cm}$. in diameter with a definite rounded firm postero-superior rim. This passed down the posterior auricular wall to disappear behind the medial end of the Eustachian valve so that the valve and the absent ring of tissue were closely related. The ease with which the two could be confused explained the operative difficulties. Two right superior pulmonary veins entered the superior vena cava below the azygos vein and the middle and inferior veins opened into the posterolateral wall of the atrium. The pulmonary artery was dilated and the remainder of the heart was normal. 


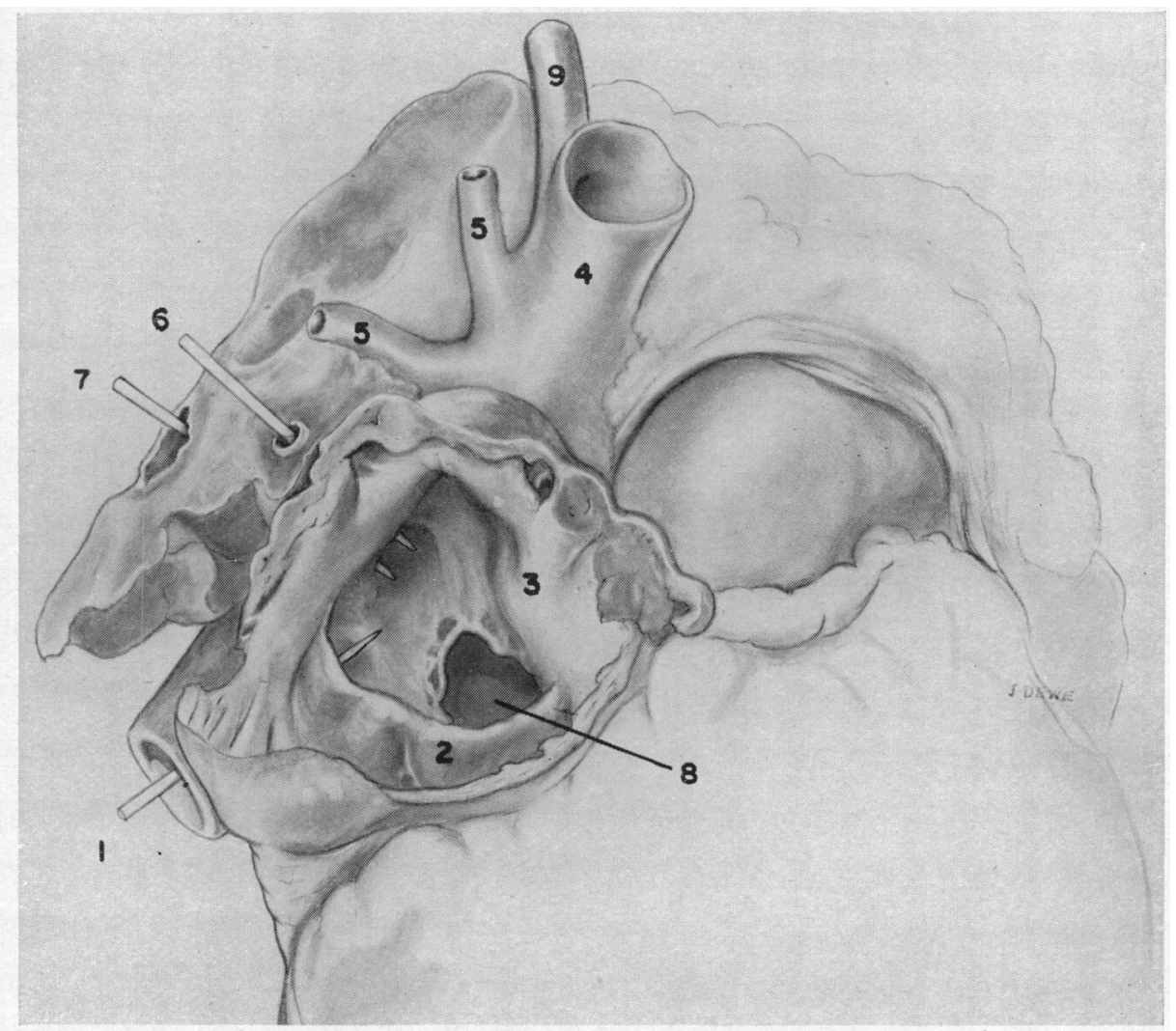

FIG. 6.-Drawing of right atrium in Case 2. (1) Inferior vena cava. (2) Eustachian valve. (3) Tubercle of Lower. (4) Superior vena cava. (5) Superior pulmonary veins. (6) Middle pulmonary veins. (7) Inferior pulmonary veins. (8) Atrial septal defect.

(9) Azygos vein.

\section{DisCUSSION}

Lancisi (1717) suggested that the Eustachian valve directed the superior caval stream away from the inferior cava in upright homo sapiens. Franklin (1948) stated that it persists only in hearts in which an element of the superior caval flow is directed towards the inferior caval orifice, there being a direct correlation between the height of the valve and the direction of the superior caval flow. In the fœtus it directs inferior caval blood across the foramen ovale (Sabatier, 1774; Barclay et al., 1944) and recently Swan et al. (1954) have suggested that right-to-left shunts are associated with the relationship of the atrial septal defect to the inferior caval stream. Persistence of the valve is more common in atrial septal defects (Yater, 1924) and may occur with Ebstein's disease (Taussig, 1947). These facts suggest a relationship to stream effects in the atrium and it may play a part in right-to-left shunts in the atrium. Several observers (Yater, 1929; Jordan, 1926; Salviati, 1945) have reported thrombi and secondary emboli in association with the valve and Chiari's network. The latter may cause arrhythmias (Yater, 1929; Jordan, 1926). A large valve may interfere with catheterization of the coronary sinus (Bing et al., 1951) or the inferior cava.

In Case 2 the valve formed a false lower rim to a defect that had no lower edge. Lewis (1955) has reported a similar arrangement in four patients. The danger of including this valve in atrial septal repairs is obvious unless it is identified by its thin sharp edge and relationship to the inferior caval opening. 


\section{SUMMARY}

The surgical repair of atrial septal defects has led to an increasing awareness of the anatomy of the right atrium and its variations.

The normal anatomy and embryology of the right atrium is described with emphasis on the valve of the inferior vena cava.

Two patients are described in whom surgical repair of atrial septal defects was attempted. In both, the valve of the inferior cava made the anatomy difficult to interpret and surgery was unsuccessful.

This valve should be identified in the repair of atrial septal defects and suggestions are made for doing this.

The valve of the inferior vena cava may play a part in right-to-left shunts and in stream effects in the atria. It may cause failure to catheterize the coronary sinus and inferior vena cava, and lead to thrombotic and embolic phenomena, and arrhythmias.

My thanks are due to Mr. N. R. Barrett and Mr. G. K. Harrison for permission to publish these cases; to Dr. T. Morris for help with the anatomy and embryology, and to Miss Joan Dewe and the Department of Medical Photography for the illustrations. In particular I am grateful to Dr. Raymond Daley for his advice and encouragement.

\section{REFERENCES}

Arey, L. B. (1954). Developmental Anatomy. 6th ed., Saunders, Phil.

Bailey, C. P., Bolton, H. E., Jamison, W. L., and Neptune, W. B. (1953). J. thorac. Surg., $26,184$.

Barclay, A., Franklin, J., and Prichard, M. (1944). The Fotal Circulation. Blackwell, London.

Bauhin, C. (1605). Theatrum Anatomica.

Bing, R. J., and Daley, R. (1951). Amer. J. Med., 10, 711.

Bjork, V. O., Crafoord, C., Jonsson, B., Kjellberg, S. R., and Rudhe, U. (1954). Acta. chir. scand., $107,499$.

Chiari, H. (1897). Anat. V.Z. Allg. Path., 22, 1.

Drury, R. A. B. (1949). J. Path. Bact., 61, 449.

Eustachius, B. (1563). Opuscula. Anatomica.

Franklin, K. J. (1948). Cardiovascular Studies. Blackwell, Oxford.

Gross, R. E., Watkins, E., Jr., Pomeranz, A. A., and Goldsmith, E. I. (1953). Surg. Gynec. Obset., $96,1$.

Harvey, W. (1628). Exercitatio Anatomica de Motu Cordis et Sanguinis in Animalibus.

Jordan, W. R. (1926). Arch. Path., 2, 840.

Keith, A. (1904). Lancet, 1, 555.

Lancisi (1717). Quoted in Morgagni, J. B. (1765). Opera Omnia Patavii, 1, 173.

Lewis, F. J. (1955). J. thorac. Surg., 29, 52.

Pan, N. (1936). J. Anat., 70, 435.

Quain's Anatomy (1929). The Heart. 11th ed., Vol. 4. Longmans Green, London.

Sabatier (1774). Mem. Acad. Roy. Sci. Paris, 198.

Salviati, L. (1945). Arch. " de Vecchi" per Anat. Path. Med. Clin., 7, 779.

Swan, J. C. R., Burchell, H. S., and Wood, E. H. (1954). Circulation, 10, 705.

Taussig, H. B. (1947). Congenital Malformations of the Heart, The Commonwealth Fund, New York.

Yater, W. M. (1929). Arch. Path., 7, 418.

Winslow, J. B. (1717). Mem. Acad. Roy. Sci. Paris, 211. 